\title{
Association between flourishing mental health and occupational stress among workers of Tsukuba Science City, Japan: a cross-sectional study
}

\author{
Daisuke Hori ${ }^{1}$, Yuichi Oi ${ }^{1}$, Yuh Ohtaki ${ }^{2}$, Christina-Sylvia Andrea ${ }^{3}$, Tsukasa Takahashi ${ }^{3}$, Nagisa Shiraki ${ }^{3}$,
} Tomohiko Ikeda ${ }^{3}$, Yu Ikeda ${ }^{3}$, Shotaro Doki ${ }^{1}$, Shinichiro Sasahara ${ }^{1 *}$ (i) and Ichiyo Matsuzaki ${ }^{1,4}$

\begin{abstract}
Background: Flourishing, defined as the coexistence of hedonic and eudaimonic well-being, is the most favorable end of the mental health spectrum. A growing body of evidence has demonstrated the association between flourishing mental health and favorable work-related outcomes. However, epidemiology of flourishing mental health is scarce in Japan. Moreover, the relationship between flourishing mental health and occupational stress has not been elaborated. Therefore, the aim of this study was to elucidate (1) the prevalence of flourishing mental health and (2) the association between flourishing mental health and occupational stress among Japanese workers.

Methods: The present survey was conducted in from February to March 2017 via an anonymous, self-administered, and web-based questionnaire among workers in Tsukuba Science City, Japan. Mental Health Continuum Short Form was used to assess flourishing mental health. We performed binomial logistic regression analyses to calculate the adjusted odds ratios (AOR) and 95\% confidence intervals (CI) of occupational stress for flourishing mental health, controlling for sociodemographic factors.

Results: A total of 7012 respondents (4402 men, 2610 women) were analyzed. The overall prevalence of flourishing mental health among the respondents was 12.4\%. Full-time (permanent) workers were less likely to be flourishing. Reward from work $(\mathrm{AOR}=2.34,95 \% \mathrm{Cl}=2.04-2.68)$, support from colleagues and superiors $(\mathrm{AOR}=1.67,95 \% \mathrm{Cl}=$ 1.44-1.94), and workload ( $A O R=1.19,95 \% \mathrm{Cl}=1.05-1.36$ ) were positively associated with flourishing mental health, whereas mental workload ( $A O R=0.65,95 \% \mathrm{Cl}=0.57-0.75$ ) was inversely associated with flourishing mental health.

Conclusions: The findings of the present study shed light on the association between flourishing mental health and occupational stress.
\end{abstract}

Keywords: Flourishing, Japan, Mental health, Occupational stress, Workplace

\section{Background}

Mental health has long been understood as the absence of mental illness; however, this definition has changed considerably over the past several decades. In 2004, the World Health Organization defined mental health as "a state of well-being in which every individual realizes his or her own potential, can cope with the normal stresses

\footnotetext{
* Correspondence: s-sshara@md.tsukuba.ac.jp

${ }^{1}$ Faculty of Medicine, University of Tsukuba, 1-1-1 Tennodai, Tsukuba, Ibaraki 305-8575, Japan

Full list of author information is available at the end of the article
}

of life, can work productively and fruitfully, and is able to make a contribution to her or his community" [1]. Since that time, the concept that "the absence of mental diseases does not imply the presence of full mental health" has become widely accepted. Previous studies have confirmed that the symptoms of mental health and mental illness do not reflect opposite ends of the same continuum, but rather, load onto two separate but related factors $[2,3]$. This means that to maintain and enhance human well-being, it is important to focus on not only mental illness, but also the level of mental health.

(c) The Author(s). 2019 Open Access This article is distributed under the terms of the Creative Commons Attribution 4.0 International License (http://creativecommons.org/licenses/by/4.0/) which permits unrestricted use, distribution, and reproduction in any medium, provided you give appropriate credit to the original author(s) and the source, provide a link to the Creative Commons license, and indicate if changes were made. The Creative Commons Public Domain Dedication waiver (http://creativecommons.org/publicdomain/zero/1.0/) applies to the data made available in this article, unless otherwise stated. 
Diener et al. [4] reported that flourishing individuals are able to develop warm, trusting relationships with others and are willing to develop their potential to grow and expand as a person.

The most favorable end of the mental health spectrum is referred to as flourishing [5], which is defined as a combination of two conceptual traditions of mental well-being: hedonic and eudaimonic well-being [6]. The hedonic tradition focuses on emotional well-being through the measurement of satisfaction with life and positive affect [7], while the eudaimonic tradition focuses on psychological well-being [8] and social well-being [9], and assesses how well individuals see themselves functioning in life, such as social contributions, social integration, autonomy, and personal growth. Measurement of flourishing is currently based on data collected via self-administered questionnaires. A number of epidemiological studies on flourishing mental health have been conducted worldwide. The prevalence of flourishing was estimated to range from 11.7 to $76.9 \%$ in general population [10-14]. Longitudinal evidence has indicated that flourishing mental health has favorable effects on individual health. A 10-year cohort study revealed that the absence of flourishing mental health was associated with increased all-cause mortality [15]. A randomized control trial showed that promoting flourishing mental health decreased anxiety and depressive symptoms [16].

In addition, a growing body of evidence has suggested the desirable correlates of flourishing and work-related outcomes. For example, flourishing employees demonstrate higher levels of productivity, put greater effort in their work, report fewer missed workdays and work-related injuries, and lower levels of health care costs [17]. In a study from New Zealand, flourishing mental health among employees predicted elevated levels of satisfaction with work-life balance and job satisfaction [18]. Among workers in South Africa, several studies suggested that flourishing in work was strongly related to person-environment fit, job satisfaction, work engagement, and organizational commitment, and negatively related to turnover intention [19-21]. These findings suggest the importance of focusing on flourishing mental health among workers, not only for individual health, but also for the organization for which they work. However, research on flourishing employees is still in its infancy and the literature is limited. Working characteristics including occupational stress affect worker's performance and motivation [22]. Therefore, it is possible that occupational stress is also associated with flourishing mental health. However, to date, the association has not been fully elaborated. If occupational stress affects workers' flourishing mental health, managers should try to change the factor that facilitates well-being to maximize work-related outcomes.

There are two reasons to worth conducting an epidemiological study on positive aspects of mental health among workers in Japan. First, research on employees' mental health in terms of well-being is scarce. In Japan, the increasing incidence of mental illness and suicide among workers has received attention for decades, and the importance of prevention of them has gained widespread acceptance [23]. By contrast, little attention is paid to positive aspects of mental health. Therefore, mental health promotion in Japan remains limited to mental illness prevention initiatives such as reducing the amount of overtime work or introducing stress check systems [24]. The reason for the current dominance of mental illness over mental health in the Japanese occupational health research field may be explained by the significant lack of epidemiological evidence related to positve aspects of mental health in the workplace. Although the traditional focus on the occupational stress-related epidemiology of depression, anxiety, burnout, absenteeism, and other adverse health outcomes has produced important evidence, it has not provided a clear picture of well-being of the working population.

Secondly, flourishing mental health can play a key role in maintaining the workforce in Japan for its beneficial effect. In 2018, the labor force in Japan was approximately 74.8 million (59.8\% of the population) and the number is declining year by year, resulting from an aging population and a falling birth rate. Considering the declining working population in Japan, the Japanese government has begun promoting the participation of women, the elderly, and people with disabilities in the workforce, including those raising small children and caring for ailing relatives to compensate for the labor shortage. It is therefore essential to cultivate flourishing mental health not only for individual health, but also for optimal functioning and productivity in the workforce.

To promote well-being and productivity in the workforce, knowledge about the prevalence and determinants of flourishing mental health is important. Such epidemiological information is also an essential component of a policy making and will contribute to the development of occupational research for workers' well-being in Japan. Therefore, to test our hypothesis that flourishing mental health is associated with work characteristics, we conducted a crosssectional, web-based survey focusing on flourishing mental health among workers in Tsukuba Science City, which is one of the largest research park cities in the world. Our aims were (1) to clarify the prevalence of flourishing mental health among Japanese workers and (2) to investigate the association between flourishing mental health and occupational stress, based on the demand-control model.

\section{Methods}

Study design and participants

This is a series of study using the dataset obtained in the 7th Living Condition and Workplace Stress Survey 
conducted by Tsukuba Science City Network (TSCN). The survey was a cross-sectional, web-based, and selfadministered and aimed to investigate the mental health status, living conditions, and workplace environments of workers in Tsukuba Science City, Japan. A total of 53 organizational members of TSCN, which had a total of 19,481 workers, agreed to participate. Either Japanese version or English version of the questionnaire was available. Further information on the methodology used in the survey is available elsewhere $[25,26]$.

The variables analyzed in this study included mental health as measured by the Japanese version of the Mental Health Continuum-Short Form (MHC-SF), the Brief Scales for Job Stress (BSJS), sex, age group, marital status, educational attainment, annual household income (in Japanese yen), type of employment, occupation, physical activity, smoking status, and self-rated health, as well as numerous other items (the details of which are reported elsewhere) [25].

\section{The MHC-SF}

The Japanese version of the MHC-SF, which is composed of 14 items, was used [11]. The first three items measure the degree of emotional well-being as defined in terms of happiness, satisfaction, and interest of life, respectively; the fourth through eighth items measure social well-being, with one item each on social acceptance, social actualization, social contribution, social coherence, and social integration, respectively; and the ninth through the fourteenth items measure psychological well-being, with one item each on autonomy, environmental mastery, personal growth, positive relations with others, purpose in life, and self-acceptance, respectively. Participants were asked to report on the following six-point scale how often they had felt the positive symptoms mentioned above over the past month: $0=$ "never", 1 = "once or twice", 2 = "about once a week", 3 = "about two or three times a week", $4=$ "almost every day", and 5 = "every day." According to Keyes et al. [12], flourishing mental health is defined as the coexistence of high hedonic well-being and high eudaimonic wellbeing. In those studies, participants were categorized as having high hedonic well-being if they scored 4 or 5 on at least one of three emotional well-being items, and as having high eudaimonic well-being if they scored 4 or 5 on at least six of eleven social and psychological wellbeing items. The MHC-SF and its subscales scores have shown high internal consistency and good discriminant validity with the hypothesized three-factor structure [27]. The MHC-SF is available in several languages and has shown excellent psychometrics and validities [12, 28-32]. The MHC-SF is translated in Japanese and used in other study [32]. However, the validity of the Japanese version has not been confirmed. Cronbach's alpha coefficients in the present study were 0.921 for emotional well-being, 0.881 for social well-being, 0.906 for psychological well-being, and 0.949 for total MHC-SF score.

\section{Occupational stress}

Chronic occupational stress perceived by the workers was assessed using the BSJS. The BSJS is a 20 -item questionnaire developed by Nishikido et al. [33] based on the demand-control model, similar to the Job Content Questionnaire [34]. We asked participants to "select the response that most closely matches your feelings with regard to the descriptions about your current working circumstances". Responses were given on a four-point rating scale (from $1=$ "disagree" to $4=$ "agree"), and the mean scores (range $=1.00-4.00$ ) were calculated for six subscales ("workload," "mental workload," "problem in personal relationships," "job control," "reward from work," and "support from colleagues and superiors"). For example, reward from work is measured by three items: "I am doing a job that I can take pride in and which is worthwhile," "my job enables me to demonstrate my abilities," and "I am doing a job that gives me a sense of accomplishment and satisfaction." Workload, mental workload, and interpersonal relationships were defined as job-related stress, whereas job control, reward from work, and support from colleagues and superiors were defined as buffers against it. A higher score indicates a higher level of job-related stress or buffer against jobrelated stress. These subscales have shown sufficiently high internal consistency and validity in occupational health research $[33,35,36]$. The Cronbach's alpha coefficients in the present study were 0.904 for workload, 0.855 for mental workload, 0.820 for interpersonal relationships, 0.864 for job control, 0.932 for reward from work, 0.845 for support from colleagues and superiors, and 0.806 for total BSJS score.

\section{Other variables}

Age group was categorized into the following five groups: "20-29," “30-39," "40-49," "50-59," and "6064" years. Respondents aged 65 years or older were excluded from the analysis because this is the age at which most of the workers in participating organizations retire. The respondents aged 65 years or older were likely reemployed for a special project or working in positions such as president or executive. Marital status was divided into three groups: "single," "divorced/bereaved," and "married." Educational attainment was categorized into four groups: "high school," "college, national institute of technology, or vocational school," "university," and "graduate school." Annual household income (Japanese yen) was classified into four groups: < 4 million, 48 million, $8-12$ million, and $\geq 12$ million (as of 
December 2018, one million yen was equivalent to about 8800 US dollars or 7800 euro). Occupation was derived from the answer to the question: "Which of the following best describes your job?," with the answer options as "researcher/academic," "technician/engineer," and "clerk/ administration." Type of employment was categorized into three groups: "part-time or temporary," "full-time (fixed-term)," and "full-time (permanent)." Physical activity was measured with the questionnaire item "How often do you exercise for more than 30 minutes?" and classified into "less than once a month," "Several times a month," "once a week," and "more than once a week." Smoking habit was assessed with the question "Are you a current smoker?" and dichotomized into smoking and nonsmoking. Self-rated health was measured with the item "In general, how do you rate your health?," with the answer options "very good," "good," "fair," and "poor"; these answers were then dichotomized into "good/very good" and "fair/poor."

\section{Statistical analysis}

First, to compare proportions across the groups with and without flourishing mental health, we used the chisquared test. In addition, we used the $t$ test to compare the mean scores on the six scales of the BSJS. Second, to identify associations between flourishing mental health and job stress, we performed a series of binomial logistic regression analyses to calculate the adjusted odds ratios (AORs) and 95\% confidence intervals (CIs). Flourishing mental health was used as the dependent variable, and six scales of the BSJS (continuous variables) were used as the independent variable. Model 1 included sex and age group, and model 2 was additionally adjusted for marital status, educational attainment, annual household income (yen), type of employment, occupation, physical activity, smoking status, and self-rated health. All statistical tests were two-tailed, and $p$ values $<0.05$ were regarded as indicating statistical significance. IBM SPSS 25 for Windows (IBM Corp., Armonk, NY) was used for all statistical analyses.

\section{Results}

Of the 19,481 workers, 7255 completed the questionnaire (response rate, 37.2\%). Participants aged 65 years and older and those who had missing values in investigated variables were excluded. Finally, data from 7012 participants were analyzed, with a valid response rate of $36.0 \%$ (7012/19481). The age distributions (mean \pm standard deviation [SD]) of the participants were 44.0 \pm 10.3 years for all participants $(n=7012), 45.0 \pm 10.5$ years for men $(n=4402)$, and $42.3 \pm 9.6$ years for women $(n=2610)$.

Table 1 summarizes the participants' descriptive characteristics. The proportions of the participants classified as having flourishing mental health as measured by the MHC-SF was $12.4 \%$. Among the participants, $37.2 \%$ were women, over $70 \%$ were married, nearly half had graduated from graduate school, and $15.1 \%$ had a household income of 12 million yen or above. In addition, $61.9 \%$ of the participants were employed full-time (permanent) and $41.6 \%$ were researchers/academics.

A comparison of characteristics between participants with flourishing and non-flourishing mental health is shown in Table 2. All variables investigated in the present study were statistically significantly associated with flourishing mental health. The scores for workload, mental workload, and problems in personal relationships were lower in the flourishing than in the non-flourishing participants. On the other hand, the scores for job control, reward from work, and support from colleagues and superiors were higher in the flourishing than in the non-flourishing participants. The participants with the following characteristics were more likely to have flourishing mental health compared with those without: aged 30-39 years, married, finished master's or doctor's degree, annual household income of more than 12 million yen, full-time staff (fixed-term), researcher/academic, exercise habit at least once a week, nonsmoking, and selfrated health as good/very good.

The results of binomial logistic regression analysis related to flourishing mental health are shown in Table 3. After adjusting for differences in sex and age, the results indicated statistically significant associations between flourishing mental health and workload, reward from work, and support from colleagues and superiors. On the contrary, mental workload was inversely associated with flourishing mental health. The statistically significant associations persisted after further controlling for marital status, educational attainment, annual household income, type of employment, occupation, physical activity, smoking status, and self-rated health. After adjusting for these factors, the results indicated statistically significant associations between flourishing mental health and workload $(\mathrm{OR}=1.19,95 \% \mathrm{CI}=1.05-1.36)$, mental workload $(\mathrm{OR}=0.65,95 \% \mathrm{CI}=0.57-0.75)$, reward from work $(\mathrm{OR}=2.34,95 \% \mathrm{CI}=2.04-2.68)$, and support from colleagues and superiors $(\mathrm{OR}=1.67,95 \% \mathrm{CI}=$ 1.44-1.94).

\section{Discussion}

The aim of this study was to estimate the prevalence of flourishing mental health and evaluate the association between flourishing mental health and occupational stress among workers in Japan. To the best of our knowledge, this is the first large-scale epidemiological study in Japan to describe the prevalence of flourishing mental health. Moreover, precedent epidemiological studies of flourishing mental health were mainly conducted among 
Table 1 Descriptive characteristics of the participants ( $n=$ 7012), Tsukuba, Japan (2017)

\begin{tabular}{|c|c|c|c|c|c|}
\hline & Percent & Number & & Percent & Number \\
\hline Mental health & & & Physical activity per week & & \\
\hline Flourishing & 12.4 & $(870)$ & Less than once & 53.3 & $(3735)$ \\
\hline Non-flourishing & 87.6 & $(6142)$ & Once or more & 46.7 & $(3277)$ \\
\hline Job-related stress, mean \pm SD & & & Smoking status & & \\
\hline Workload & 2.16 & \pm 0.88 & Currently smoking & 10.8 & $(757)$ \\
\hline Mental workload & 2.22 & \pm 0.86 & Not smoking & 89.2 & $(6255)$ \\
\hline Problem in personal relationships & 2.00 & \pm 0.79 & Self-rated health & & \\
\hline Buffer against job-related stress, mean \pm SD & & & Poor/fair & 15.7 & $(1098)$ \\
\hline Job control & 2.76 & \pm 0.76 & Good/very good & 84.3 & $(5914)$ \\
\hline
\end{tabular}

Table 1 Descriptive characteristics of the participants ( $n=$ 7012), Tsukuba, Japan (2017) (Continued) $\pm 0.69$

(4402)

(2610)

Women

Age group

20-29

30-39

40-49

50-59

60-64

Marital status

Never married

Divorced/bereaved

Married

Educational attainment

High school

College, etc.

University

Graduate school

Annual household income (yen)

Less than 4 million

4-8 million

8-12 million

12 million or above

Type of employment

Part-time, temporary

Full-time (fixed-term)

Full-time (permanent)

Occupation

Researcher/academic

Technician/engineer

Clerk/administration

\section{$(2920)$}

(1578)

(2514) the general population. Therefore, our results advanced the existing literature by providing evidence on occupational settings.

\section{Prevalence of flourishing among workers}

Our study revealed that $12.4 \%$ of workers had flourishing mental health. Because there is no epidemiological study regarding the prevalence of flourishing in Japan, we compared the result with that from the other countries. Our result showed smaller prevalence than that in Canada (76.9\%) [10], in the Netherlands (36.5\%) [14], in South Africa $(20.0 \%)$ [12], or in the USA (18.1\%) [11]. On the other hand, our result showed slightly greater prevalence than that in South Korean adults (11.7\%) [13]. Few epidemiological studies have examined the prevalence of flourishing mental health among workers. One exception is Hone et al. [18] who reported that $25 \%$ of workers in New Zealand were flourishing. Our findings suggest that there is much room for improvement in flourishing mental health among Japanese workers, compared to people in other countries. However, the result should be interpreted with caution because the assessment of flourishing, culture, subject sampling, age range, and geography differed from study to study. A sevenfold difference in the prevalence of flourishing was found between the lowest and highest countries in general population, which suggests cultural factors play a role in determining the prevalence. Iwata et al. have indicated the suppression of expression of positive emotions by the Japanese [37, 38]. Another possible explanation for the low level of mental health in the current study is the higher level of national inequality and collectivism, which are known to be predictors of subjective well-being across countries [39]. However, it remains unknown whether these factors affect the prevalence of flourishing mental health among workers.

\section{Flourishing mental health and occupational stress}

Flourishing workers appeared to enjoy fewer demanding jobs, less conflict with others, higher job control, higher 
Table 2 Comparison of characteristics between flourishing and non-flourishing mental health ( $n=7012)$, Tsukuba, Japan (2017)

\begin{tabular}{|c|c|c|c|c|c|}
\hline & \multicolumn{2}{|c|}{ Flourishing } & \multicolumn{2}{|c|}{ Non-flourishing } & \multirow{2}{*}{$\begin{array}{l}p \\
\text { value }\end{array}$} \\
\hline & $\%$ & $(n)$ & $\%$ & $(n)$ & \\
\hline \multicolumn{6}{|l|}{ Job-related stress, mean \pm SD } \\
\hline Workload & 2.09 & \pm 0.89 & 2.17 & \pm 0.88 & 0.009 \\
\hline Mental workload & 2.01 & \pm 0.84 & 2.25 & \pm 0.86 & $<0.001$ \\
\hline Problem in personal relationships & 1.73 & \pm 0.75 & 2.94 & \pm 0.78 & $<0.001$ \\
\hline \multicolumn{6}{|l|}{ Buffer against job-related stress, mean $\pm \mathrm{SD}$} \\
\hline Job control & 3.11 & \pm 0.78 & 2.71 & \pm 0.75 & $<0.001$ \\
\hline Reward from work & 3.36 & \pm 0.77 & 2.69 & \pm 0.84 & $<0.001$ \\
\hline Support from colleagues and superiors & 3.20 & \pm 0.68 & 2.72 & \pm 0.67 & $<0.001$ \\
\hline Sex & & & & & 0.003 \\
\hline Men & 11.5 & $(506)$ & 88.5 & (3896) & \\
\hline Women & 13.9 & $(364)$ & 86.1 & $(2246)$ & \\
\hline Age group & & & & & $<0.001$ \\
\hline $20-29$ & 13.1 & $(86)$ & 86.9 & (568) & \\
\hline $30-39$ & 16.8 & $(305)$ & 83.2 & (1513) & \\
\hline $40-49$ & 10.9 & $(240)$ & 89.1 & $(1960)$ & \\
\hline $50-59$ & 10.1 & $(191)$ & 89.9 & $(1694)$ & \\
\hline $60-64$ & 10.5 & $(48)$ & 89.5 & $(407)$ & \\
\hline Marital status & & & & & 0.001 \\
\hline Never married & 10.5 & $(190)$ & 89.5 & (1614) & \\
\hline Divorced/bereaved & 8.0 & $(21)$ & 92.0 & (243) & \\
\hline Married & 13.3 & $(659)$ & 86.7 & $(4285)$ & \\
\hline Educational attainment & & & & & $<0.001$ \\
\hline High school & 8.3 & (77) & 91.7 & (846) & \\
\hline College, etc. & 9.1 & (75) & 90.9 & (748) & \\
\hline University & 12.1 & $(228)$ & 87.9 & $(1663)$ & \\
\hline Graduate school & 14.5 & $(490)$ & 85.5 & $(2885)$ & \\
\hline Annual household income (yen) & & & & & 0.014 \\
\hline Less than 4 million & 12.2 & $(132)$ & 87.8 & (950) & \\
\hline 4-8 million & 10.8 & $(272)$ & 89.2 & $(2242)$ & \\
\hline 8-12 million & 13.6 & $(321)$ & 86.4 & (2038) & \\
\hline 12 million or above & 13.7 & $(145)$ & 86.3 & (912) & \\
\hline Type of employment & & & & & $<0.001$ \\
\hline Part-time, temporary & 13.7 & (199) & 86.3 & $(1249)$ & \\
\hline Full-time (fixed-term) & 16.6 & $(203)$ & 83.4 & $(1020)$ & \\
\hline Full-time (permanent) & 10.8 & $(468)$ & 89.2 & (3873) & \\
\hline Occupation & & & & & $<0.001$ \\
\hline Researcher/academic & 15.3 & $(448)$ & 84.7 & $(2472)$ & \\
\hline Technician/engineer & 11.0 & $(174)$ & 89.0 & $(1404)$ & \\
\hline Clerk/administration & 9.9 & $(248)$ & 90.1 & $(2266)$ & \\
\hline Physical activity per week & & & & & $<0.001$ \\
\hline Less than once & 10.7 & (399) & 89.3 & (3336) & \\
\hline Once or more & 14.4 & $(471)$ & 85.6 & $(2806)$ & \\
\hline
\end{tabular}

Smoking status 
Table 2 Comparison of characteristics between flourishing and non-flourishing mental health ( $n=7012)$, Tsukuba, Japan (2017) (Continued)

\begin{tabular}{|c|c|c|c|c|c|}
\hline & \multicolumn{2}{|c|}{ Flourishing } & \multicolumn{2}{|c|}{ Non-flourishing } & \multirow{2}{*}{$\begin{array}{l}p \\
\text { value }\end{array}$} \\
\hline & $\%$ & (n) & $\%$ & (n) & \\
\hline Currently smoking & 9.8 & (74) & 90.2 & (683) & \\
\hline Not smoking & 12.7 & (796) & 87.3 & (5459) & \\
\hline Self-rated health & & & & & $<0.001$ \\
\hline Poor/fair & 4.3 & (47) & 95.7 & $(1051)$ & \\
\hline Good/very good & 13.9 & (823) & 86.1 & $(5091)$ & \\
\hline
\end{tabular}

SD standard deviation

Statistical analyses were conducted with chi-squared test and $t$ test

rewards from work, and higher support compared with their non-flourishing peers. In terms of the demandcontrol model for occupational stress, the above results imply that flourishing workers tend to have a low strain job, which is defined as a job with low psychological demands and high job decision latitude. It is suggested that the risk of psychological strain and physical illness are lower in this condition compared with active jobs (high demands/high job decision latitude), high strain jobs (high demands/low job decision latitude), and passive jobs (low demands/low job decision latitude) [40]. This is in accordance with precedent studies suggesting a relationship between flourishing mental health and favorable health outcomes $[15,41]$. It is possible that the characteristics of the participants in the present study affected the prevalence of flourishing mental health as the majority were scientific researchers, who have been reported to enjoy a high level of job decision latitude [40].

Reward from work and support from colleagues and superiors were statistically significantly associated with flourishing mental health in the fully adjusted logistic regression analysis; these associations with were in-line with a precedent study [42]. Among the BSJS subscale scores, reward from work had the most influence on flourishing mental health. The result implies that retaining a focus on workers' sense of that their job is worth doing, sense of using their strengths, and sense of accomplishment play an important role in flourishing mental health. Although it is practically difficult to improve the work environment, such as raising wages or reducing sales quotas, it might be possible to improve workers' flourishing mental health via positive relationships in workplace. Acknowledgements, recognition, respect, or gratitude paid by workers' colleagues and superiors could promote a sense of support among workers, as well as a feeling that their work is rewarding. Encouraging such mutual acts in the workplace might serve as an effective intervention to increase flourishing mental health. For example, Page and Vella-Brodrick [43] developed the working for wellness program for employee, which consisted of sessions to learn applying their strengths, or optimizing relationships at and outside of work.

Our results also showed that flourishing mental health was inversely associated with mental workload. It is essential for managers to support subordinate who are facing troubles or help new employees to orient themselves toward their work so that they can reduce their mental workload. Moreover, our result indicated that reducing mental workload only while keeping appropriate workload could be more effective in terms of maintaining good mental health. This was an important finding because managers often try to reduce both workloads as a countermeasure against mental illness. Managers should take this into account by monitoring employees' perceived workloads to maximize the mental health in workplace.

\section{Flourishing mental health and other variables}

It is noteworthy that part-time and temporary workers were significantly more flourishing than full-time (permanent) workers, after controlling for differences in household income and other socioeconomic factors. It is plausible that part-time or temporary workers experience more flourishing than full-time (permanent) workers because they generally have more free time and less workload. However, because of the cross-sectional design of the present study, it might be premature to conclude from our findings that part-time or temporary employment is good for well-being, as it is unstable compared with full-time employment. If a person is underemployed, working below their full capacity, or working for fewer hours than desired, unstable employment has a negative effect on mental health $[44,45]$. Kume et al. [46] pointed out that involuntary part-time employment is negatively associated with subjective happiness. Future studies should therefore address the issue of whether the participants' present type of employment is voluntary or involuntary.

We identified a pattern of gradually decreasing numbers of flourishers with increasing age. This gradual pattern for age group is in accordance with a report in 
Table 3 Binomial logistic regression analysis related to flourishing mental health ( $n=7012)$, Tsukuba, Japan (2017)

\begin{tabular}{|c|c|c|c|c|}
\hline & \multicolumn{2}{|c|}{ Sex and age group adjusted } & \multicolumn{2}{|c|}{ Fully adjusted } \\
\hline & $\overline{\mathrm{AOR}}$ & $95 \% \mathrm{Cl}^{\mathrm{a}}$ & $\overline{\mathrm{AOR}}$ & $95 \% \mathrm{Cl}^{\mathrm{a}}$ \\
\hline \multicolumn{5}{|l|}{ Job-related stress (continuous) } \\
\hline Workload & 1.21 & $1.06-1.36$ & 1.19 & $1.05-1.36$ \\
\hline Mental workload & 0.62 & $0.54-0.71$ & 0.65 & $0.57-0.75$ \\
\hline Problem in personal relationships & 0.90 & $0.80-1.01$ & 0.93 & $0.82-1.05$ \\
\hline \multicolumn{5}{|l|}{ Buffer against job-related stress (continuous) } \\
\hline Job control & 1.09 & $0.97-1.24$ & 1.08 & $0.95-1.23$ \\
\hline Reward from work & 2.43 & $2.14-2.77$ & 2.34 & $2.04-2.68$ \\
\hline Support from colleagues and superiors & 1.68 & $1.45-1.94$ & 1.67 & $1.44-1.94$ \\
\hline \multicolumn{5}{|l|}{ Sex } \\
\hline Men, reference & 1.00 & & 1.00 & \\
\hline Women & 1.30 & $1.10-1.54$ & 1.28 & $1.05-1.56$ \\
\hline \multicolumn{5}{|l|}{ Age group } \\
\hline 20-29, reference & 1.00 & & 1.00 & \\
\hline $30-39$ & 1.24 & $0.94-1.64$ & 1.05 & $0.78-1.43$ \\
\hline $40-49$ & 0.85 & $0.64-1.12$ & 0.71 & $0.52-0.98$ \\
\hline $50-59$ & 0.82 & $0.61-1.10$ & 0.67 & $0.47-0.94$ \\
\hline $60-64$ & 0.82 & $0.54-1.22$ & 0.56 & $0.36-0.87$ \\
\hline
\end{tabular}

Marital status

Never married, reference

1.00

Divorced/bereaved

0.97

$0.58-1.63$

Married

Educational attainment

High school, reference

1.00

College, etc.

$0.61-1.25$

University

Graduate school

Annual household income (yen)

Less than 4 million, reference

4-8 million

8-12 million

12 million or above

Type of employment

Part-time, temporary, reference

Full-time (fixed-term)

1.00

Full-time (permanent)

Occupation

Researcher/academic, reference

Clerk/administration

Physical activity per week

Less than once 
Table 3 Binomial logistic regression analysis related to flourishing mental health $(n=7012)$, Tsukuba, Japan (2017) (Continued)

\begin{tabular}{|c|c|c|c|c|}
\hline & \multicolumn{2}{|c|}{ Sex and age group adjusted } & \multicolumn{2}{|c|}{ Fully adjusted } \\
\hline & $\overline{A O R}$ & $95 \% \mathrm{Cl}^{\mathrm{a}}$ & $\overline{A O R}$ & $95 \% \mathrm{Cl}^{a}$ \\
\hline Currently smoking, reference & & & 1.00 & \\
\hline Not smoking & & & 1.11 & $0.84-1.45$ \\
\hline \multicolumn{5}{|l|}{ Self-rated health } \\
\hline Poor/fair, reference & & & 1.00 & \\
\hline Good/very good & & & 1.88 & $1.37-2.59$ \\
\hline Nagelkerke $R^{2}$ & 0.19 & & 0.21 & \\
\hline
\end{tabular}

$O R$ odds ratio, $\mathrm{Cl}$ confidence interval

${ }^{\text {a }} 95 \% \mathrm{Cl}$ is shown as "lower-bound-upper-bound"

which adults in Japan aged 50-59 years reported the lowest level of happiness [47]. This finding is in contrast with Keyes and Simoes [15], who reported finding the highest rate of flourishers in the 45-54-year-old group in the USA. Thus, older workers in Japan might be a good target for promoting flourishing mental health. Female or married participants were more likely to have flourishing mental health. This finding was in agreement with other studies in terms of predictors of flourishing mental health $[10,15,48]$. On the contrary, the highest level of educational attainment and household income was not significantly associated with flourishing mental health after controlling for other factors. It is possible that high income and educational background are not requirements for flourishing mental health in Japanese workers. This result suggests that mental health promotion strategies in workplace should be aimed at enhancing social rewards and support instead of raising wages.

The result of the multinomial logistic regression analysis indicated that self-rated health plays an important role in relation to flourishing mental health. Although more than $80 \%$ of the participants rated their health as good or very good, only $12.4 \%$ were categorized as having flourishing mental health. Other studies have also identified a gap between flourishing mental and self-rated health [13, 49]. This result implies that perceived health is not a sufficient condition for flourishing mental health. It is therefore essential to pay attention not only to workers' general health, but also to their positive aspects of mental health.

\section{Strengths and limitations}

The present study had several strengths. To our knowledge, this is the first study to demonstrate the prevalence of flourishing mental health among Japanese workers. Moreover, we showed association between flourishing mental health and occupational stress. Previous epidemiological studies on flourishing mental health have been conducted mainly in Western countries and with general populations. In addition, our study had a considerable sample size, with a total of 7012 workers.
However, the present study also had some limitations. First, the validity of the Japanese version of the MHCSF, main outcome of the current study, has not been confirmed in precedent studies. Future research is needed to establish validity and utility of the Japanese version of the MHC-SF. Second, because of the crosssectional design, causal relationships could not be determined. The mechanisms underlying the association between flourishing mental health and job stress therefore remains unclear. Flourishing workers might be engaging in their work enthusiastically so that they can gain social rewards or support in the workplace, or vice versa. A longitudinal study is therefore required to disentangle the causal relationships between flourishing mental health and occupational stress. Third, the response rate was relatively low, so there may have been a nonresponse or other type of bias that could have affected the results. A number of participants, especially nonflourishing workers, might have been reluctant to respond to the questionnaire. Thus, our results regarding the prevalence of flourishing mental health might be overestimated. Future survey with high response rate is needed to clarify the accurate prevalence. Fourth, our target population was not a random sample from the general working population in Japan. Our participants included many researchers, highly educated and earning individuals. Moreover, Kageyama et al. revealed that scientific researchers had higher score of "reward from work" than other job [36]. Therefore, it is possible that the prevalence of flourishing might be overestimated in our study. Some caution is therefore required when generalizing the findings to workers in general. Fifth, not all factors related to flourishing mental health were considered in the current study. For example, medical history, drinking status, and objective workrelated indicators, such as working hours, should also be considered in a future study. Lastly, all data were gathered from self-administered measures. Therefore, there is a possibility that a part of the observed significant associations may be attributed to commonmethod bias. 


\section{Conclusion}

Our study revealed that $12.4 \%$ of workers in Tsukuba Science City had flourishing mental health. This is the first large epidemiological study in Japan to demonstrate the prevalence of flourishing mental health. Moreover, our findings shed light on the association between occupational stress and flourishing mental health. These results are useful in developing positive mental health promotion strategies. Undoubtedly, further research on flourishing mental health in Japan is needed. The effect of flourishing mental health on illness, mortality, and other important public health outcomes had not yet elucidated in the East Asia.

\section{Abbreviations \\ AOR: Adjusted odds ratio; BSJS: Brief Scales for Job Stress; MHC-SF: Mental Health Continuum Short Form; OR: Odds ratio; SD: Standard deviation; TSCN: Tsukuba Science City Network}

\section{Acknowledgements}

We thank the all participants and staffs of TSCN for their support to this study.

\section{Authors' contributions}

$\mathrm{DH}, \mathrm{Y}$ Oi, SD, SS, and IM conceived, designed, and coordinated the study. Y Ohtaki and CSA contributed to the translation of the questionnaire. DH, Y Oi, Y Ohtaki, CSA, TT, NS, SD, SS, and IM contributed to conduct the crosssectional survey and collect the data. DH and SS performed and supervised the statistical analysis of data and prepared the first draft of the manuscript. Y Oi, Y Ohtaki, CSA, TT, NS, TI, YI, SD, SS, and IM provided the feedback and suggestions in interpreting the findings, critically revised the manuscript, and contributed to the final draft. All authors read the final version of the manuscript and approved to submission.

\section{Funding}

No external funding was received for this study.

\section{Availability of data and materials}

The data that support the findings of this study are available from TSCN but restrictions apply to the availability of these data, which were used under license for the current study, and so are not publicly available. Data are however available from the authors upon reasonable request and with permission of TSCN.

\section{Ethics approval and consent to participate}

Ethical approval to conduct the present study was obtained from the Ethics Committee of Faculty of Medicine, Tsukuba University (No. 1374). All procedures were performed in accordance with the ethical standards of the institutional and/or national research committees and the 1964 Helsinki Declaration and its later amendments, or comparable ethical standards. The consent to participate was implied by completion of the questionnaire. Before starting the survey, respondents who gave their consent to participate chose the answer "yes, I agree to the terms and conditions," and therefore, they could proceed to the questionnaire. Respondents who did not give their consent to participate chose the answer "no, I do not agree," and they could not proceed to the questionnaire.

\section{Consent for publication}

No identifiable individual participation data are contained in the manuscript.

\section{Competing interests}

$\mathrm{DH}, \mathrm{Y}$ Oi, SD, SS, and IM are members of the Occupational Health Committee of TSCN, without pay.

\section{Author details}

${ }^{1}$ Faculty of Medicine, University of Tsukuba, 1-1-1 Tennodai, Tsukuba, Ibaraki 305-8575, Japan. ${ }^{2}$ Hospital Bando, 411 Kutsukake, Bando, Ibaraki 306-0515,
Japan. ${ }^{3}$ Graduate School of Comprehensive Human Sciences, University of Tsukuba, 1-1-1 Tennodai, Tsukuba, Ibaraki 305-8575, Japan. ${ }^{4}$ International Institute for Integrative Sleep Medicine, University of Tsukuba, 1-1-1 Tennodai, Tsukuba, Ibaraki 305-8575, Japan.

Received: 31 March 2019 Accepted: 10 October 2019

Published online: 27 November 2019

\section{References}

1. World Health Organization. Promoting mental health. 2004. http://www. who.int/mental_health/evidence/en/promoting_mhh.pdf. Accessed 11 Mar 2018.

2. Keyes $\mathrm{CL}$. Mental illness and/or mental health? Investigating axioms of the complete state model of health. J Consult Clin Psychol. 2005;73:539-48.

3. Westerhof GJ, Keyes CL. Mental illness and mental health: the two continua model across the lifespan. J Adult Dev. 2010;17:110-9.

4. Diener E, Wirtz D, Tov W, Kim-Prieto C, Choi D-W, Oishi S, et al. New wellbeing measures: short scales to assess flourishing and positive and negative feelings. Soc Indic Res. 2010;97:143-56.

5. Keyes $\mathrm{CL}$. Promoting and protecting mental health as flourishing: a complementary strategy for improving national mental health. Am Psychol. 2007:62:95-108.

6. Keyes $\mathrm{CL}$, Annas J. Feeling good and functioning well: distinctive concepts in ancient philosophy and contemporary science. J Posit Psychol. 2009;4: 197-201.

7. Diener E. Subjective well-being: the science of happiness and a proposal for a national index. Am Psychol. 2000;55:34-43.

8. Ryff $\mathrm{CD}$, Singer $\mathrm{BH}$. Know thyself and become what you are: a eudaimonic approach to psychological well-being. In: Delle Fave A, editor. The exploration of happiness. Springer; 2013. p. 97-116.

9. Keyes CL. Social well-being. Soc Psychol Q. 1998;61:121-40.

10. Gilmour H. Positive mental health and mental illness. Health Rep. 2014; 25:3-9.

11. Keyes $C L$. The mental health continuum: from languishing to flourishing in life. J Health Soc Behav. 2002:43:207-22

12. Keyes $C L$, Wissing $M$, Potgieter JP, Temane M, Kruger A, Van Rooy S. Evaluation of the mental health continuum-short form (MHC-SF) in setswana-speaking South Africans. Clin Psychol Psychother. 2008;15:181-92.

13. Lim YJ, Ko YG, Shin HC, Cho Y. Prevalence and correlates of complete mental health in the South Korean adult population. In: Keyes $\mathrm{CL}$, editor. Mental well-being. Springer; 2013. p. 91-109.

14. Schotanus-Dijkstra M, Pieterse ME, Drossaert CH, Westerhof GJ, De Graaf R, Ten Have $M$, et al. What factors are associated with flourishing? Results from a large representative national sample. J Happiness Stud. 2016;17:1351-70.

15. Keyes CL, Simoes EJ. To flourish or not: positive mental health and all-cause mortality. Am J Public Health. 2012;102:2164-72.

16. Schotanus-Dijkstra M, Drossaert CH, Pieterse ME, Boon B, Walburg JA, Bohlmeijer ET. An early intervention to promote well-being and flourishing and reduce anxiety and depression: a randomized controlled trial. Internet interventions. 2017;9:15-24.

17. Keyes CL, Grzywacz JG. Health as a complete state: the added value in work performance and healthcare costs. J Occup Environ Med. 2005;47:523-32.

18. Hone LC, Jarden A, Duncan S, Schofield GM. Flourishing in New Zealand workers: associations with lifestyle behaviors, physical health, psychosocial, and work-related indicators. J Occup Environ Med. 2015;57:973-83.

19. Diedericks E, Rothmann S. Flourishing of information technology professionals: the role of work engagement and job satisfaction. J Psychol Afr. 2013;23:225-33.

20. Diedericks E, Rothmann S. Flourishing of information technology professionals: effects on individual and organisational outcomes. S Afr J Bus Manag. 2014;45:27-41.

21. Janse van Rensburg C, Rothmann SS, Diedericks E. Person-environment fit, flourishing and intention to leave in universities of technology in South Africa. S Afr J Ind Psychol. 2017;43:1-10.

22. Deng J, Guo Y, Ma T, Yang T, Tian X. How job stress influences job performance among Chinese healthcare workers: a cross-sectional study. Environ Health Prev Med. 2019;24:2.

23. Inoue K, Matsumoto M. Karo jisatsu (suicide from overwork): a spreading occupational threat. Occup Environ Med. 2000;57:284-5.

24. Imamura K, Asai Y, Watanabe K, Tsutsumi A, Shimazu A, Inoue A, et al. Effect of the National Stress Check Program on mental health among workers in 
Japan: a 1-year retrospective cohort study. Journal of occupational health. 2018:60:298-306.

25. Occupational Health Committee of the Tsukuba Science City Network. Tsukuba kenkyu gakuen toshi tou shokuin no dai 7 kai seikatsu kankyo syokuba sutoresu chosa hokokusyo. 2019. http://www.tsukuba-network.jp/ katsudo/teigen/pdf/07_stress.pdf. Accessed 27 Aug 2019.

26. Hori D, Takao S, Kawachi I, Ohtaki Y, Andrea CS, Takahashi T, et al. Relationship between workplace social capital and suicidal ideation in the past year among employees in Japan: a cross-sectional study. BMC Public Health. 2019;19:919.

27. Lamers S, Westerhof GJ, Bohlmeijer ET, ten Klooster PM, Keyes CL. Evaluating the psychometric properties of the mental health continuumshort form (MHC-SF). J Clin Psychol. 2011;67:99-110.

28. Karaś $\mathrm{D}$, Cieciuch J, Keyes $\mathrm{CL}$. The polish adaptation of the mental health continuum-short form (MHC-SF). Pers Individ Dif. 2014:69:104-9.

29. Lim YJ. Psychometric characteristics of the Korean Mental Health Continuum-Short Form in an adolescent sample. J Psychoeduc Assess. 2014:32:356-64.

30. Perugini MLL, de la Iglesia G, Solano AC, Keyes CL. The mental health continuum-short form (MHC-SF) in the Argentinean context: Confirmatory factor analysis and measurement invariance. Eur J Psychol. 2017;13:93-108.

31. Petrillo G, Capone V, Caso D, Keyes CL. The Mental Health Continuum-Short Form (MHC-SF) as a measure of well-being in the Italian context. Soc Indic Res. 2015;121:291-312.

32. Żemojtel-Piotrowska M, Piotrowski JP, Osin EN, Cieciuch J, Adams BG, Ardi R, et al. The mental health continuum-short form: the structure and application for cross-cultural studies-A 38 nation study. J Clin Psychol. 2018;74:1034-52.

33. Nishikido N, Kageyama T, Kobayasi T, Haratani T. Assessment of job stress using a brief questionnaire: its relations to depression among male workers of an information processing company. Jpn J Occup Mental Health. 2000:8:73-82.

34. Karasek R, Brisson C, Kawakami N, Houtman I, Bongers P, Amick B. The Job Content Questionnaire (JCQ): an instrument for internationally comparative assessments of psychosocial job characteristics. J Occup Health Psychol. 1998; $3: 322-55$

35. Haoka T, Sasahara S, Tomotsune Y, Yoshino S, Maeno T, Matsuzaki I. The effect of stress-related factors on mental health status among resident doctors in Japan. Med Educ. 2010;44:826-34.

36. Kageyama T, Matsuzaki I, Morita N, Sasahara S, Satoh S, Nakamura H. Mental health of scientific researchers. I. Characteristics of job stress among scientific researchers working at a research park in Japan. Int Arch Occup Environ Health. 2001;74:199-205.

37. Iwata N, Roberts CR, Kawakami N. Japan-US comparison of responses to depression scale items among adult workers. Psychiatry Res. 1995;58:237-45.

38. Iwata N, Umesue M, Egashira K, Hiro H, Mizoue T, Mishima N, et al. Can positive affect items be used to assess depressive disorders in the Japanese population? Psychol Med. 1998;28:153-8.

39. Diener E, Suh EM, Smith H, Shao L. National differences in reported subjective well-being: why do they occur? Soc Indic Res. 1995;34:7-32.

40. Karesek R, Theorell T. Healthy work. Stress, productivity and the reconstruction of work life. New York: Basic Books Inc.; 1990.

41. Schotanus-Dijkstra M, Ten Have M, Lamers SMA, de Graaf R, Bohlmeijer ET. The longitudinal relationship between flourishing mental health and incident mood, anxiety and substance use disorders. Eur J Public Health 2017;27:563-8.

42. Bakker AB, Sanz-Vergel Al. Weekly work engagement and flourishing: the role of hindrance and challenge job demands. J Vocat Behav. 2013;83:397-409.

43. Page KM, Vella-Brodrick DA. The working for wellness program: RCT of an employee well-being intervention. J Happiness Stud. 2013;14:1007-31.

44. McKee-Ryan FM, Harvey J. "I have a job, but...": a review of underemployment. J Manag. 2011;37:962-96.

45. Milner A, King TL, LaMontagne AD, Aitken Z, Petrie D, Kavanagh AM Underemployment and its impacts on mental health among those with disabilities: evidence from the HILDA cohort. J Epidemiol Community Health. 2017;71:1198-202.

46. Kume K, Otake F, Okuhira H, Tsuru K. Hi-seiki rodosya no kofukudo. 2011. https://www.rieti.go.jp/jp/publications/dp/1 1j061.pdf. Accessed 20 Mar 2018.

47. Watabe R, Kono S. 25 nendo Seikatsu no sitsu ni kansuru cyosa (setai cyosa: houmon ryuchiho) no kekka ni tsuite. 2014. http://www.esri.go.jp/jp/archive/ e_rnote/e_rnote030/e_rnote024.pdf. Accessed 11 Mar 2018.
48. Khumalo I, Temane Q, Wissing M. Socio-demographic variables, general psychological well-being and the mental health continuum in an African context. Soc Indic Res. 2012;105:419-42.

49. Huppert FA, So TT. Flourishing across Europe: Application of a new conceptual framework for defining well-being. Soc Indic Res. 2013;110: 837-61.

\section{Publisher's Note}

Springer Nature remains neutral with regard to jurisdictional claims in published maps and institutional affiliations.
Ready to submit your research? Choose BMC and benefit from:

- fast, convenient online submission

- thorough peer review by experienced researchers in your field

- rapid publication on acceptance

- support for research data, including large and complex data types

- gold Open Access which fosters wider collaboration and increased citations

- maximum visibility for your research: over $100 \mathrm{M}$ website views per year

At BMC, research is always in progress.

Learn more biomedcentral.com/submissions 